\title{
Mateus Schreiner Garcez Lopes
}

\section{Produção de plásticos biodegradáveis utilizando hidrolisado hemicelulósico de bagaço de cana-de-açúcar}

Tese apresentada ao Programa de PósGraduação Interunidades em Biotecnologia USP - Instituto Butantan

- IPT, para obtenção do Título de Doutor em Biotecnologia

Área de concentração: Biotecnologia

Orientador: Luiziana Ferreira da Silva

São Paulo

2010 


\section{RESUMO}

Lopes MSG. Produção de plásticos biodegradáveis utilizando hidrolisado hemicelulódico de bagaço de cana-de-açúcar. $128 \mathrm{f}$. Tese (Doutorado em Biotecnologia) Instituto de Ciências Biomédicas , Universidade de São Paulo, São Paulo, 2010.

Polihidroxialcanoatos (PHA), que incluem poli-3-hidroxibutirato (P3HB) e poli-3-hidroxibutiratoco-3-hidroxivalerato (PHB-co-3HV), são uma família de polímeros biodegradáveis que podem ser produzidos utilizando bagaço de cana-de-açúcar, possibilitando a sua competitividade econômica dos PHA, em relação aos congêneres petroquímicos. A xilose, presente no bagaço de cana-deaçúcar, pode ser recuperada através da hidrólise ácida mais facilmente e em melhores rendimentos do que a glicose proveniente da celulose. Assim, o objetivo deste trabalho é produzir PHA a partir de hidrolisado hemicelulósico de bagaço de cana-de-açúcar. Um programa de bioprospecção destacou duas linhagens capazes de produzir PHA a partir de xilose: Bacillus sp. MA3.3 e Burkholderia sacchari IPT101 (utilizada como controle). Foram identificados, também, dois problemas principais na utilização de xilose: (i) aumentar a produtividade em xilose, cerca de $40 \%$ menor do que em glicose, e (ii) reduzir a repressão catabólica da glicose. Propôs-se, que maior consumo de xilose porderia aumentar a velocidade de crescimento neste açúcar. Porém, a superexpressão da xilose isomerase, gene-chave do catabolismo de xilose, não resultou no incremento do crescimento de IPT101. Por esta razão, utilizaram-se balanços estequiométricos e análises de fluxos metabólicos in silico para estudar a síntese P3HB a partir de xilose. Simulações in silico indicaram que é possível aumentar o rendimento PHA a partir de xilose de $0.25 \mathrm{~g} \mathrm{~g}^{-1} \mathrm{para}^{-}$ $0.40 \mathrm{~g} \mathrm{~g}^{-1}$. Para isso, três modificações são apontadas: (i) redução do fluxo do ciclo do ácido tricarboxílico (TCA), (ii) aumento do fluxo na parte inferior na via das pentoses e (iii) aumento na atividade das enzimas de catabolismo de xilose. Em bactérias o sistema fosfoenolpiruvatofosfotransferase (PTS) é responsável pelo transporte de açúcares e regulação da repressão catabólica através de fatores de transcrição. Em Gram negativas, o regulador é o complexo CRPAMPc e para Gram positivas, é a proteína CcpA. Dois mutantes com repressão catabólica parcialmente abolida foram obtidos a partir de IPT101 e MA3.3, B. sacchari PTS Glicose ${ }^{+}$e Bacillus sp. $\triangle$ CcpA. Para ambos, verificou-se consumo simultâneo de carboidratos e redução do tempo de consumo dos açúcares no meio de cultura. Porém, diferenças de fluxos de carbono, especialmente um fluxo maior no TCA, resultaram em menores valores de biomassa e produção de PHA. Em experimentos com o hidrolisado de bagaço de cana-de-açúcar, IPT101 e MA3.3 apresentaram crescimento inibido. Por esta razão, em um novo programa de bioprospecção selecionou a linhagem Burkholderia sp. F24 devido à sua capacidade de utilizar todos os compostos orgânicos do hidrolisado para produzir PHA. Em experimentos, em biorreator, em cultivos em altas densidades celulares, obteve-se $25.04 \mathrm{~g} \mathrm{l}^{-1}$ de biomassa, $49.31 \%$ de acúmulo de P3HB na massa seca celular, alcançando assim, uma produtividade volumétrica de $0.28 \mathrm{~g} \mathrm{l}^{-1} \mathrm{~h}^{-1}$. Demonstrou-se a possibilidade de se alcançar densidades celulares ainda mais altas utilizando hidrolisados ainda mais concentrados. Além disso, foi possível controlar a fração molar de 3HV na síntese PHB-3HV em F24 utilizando xilose e ácido levulínico.

Conclui-se que o redirecionamento de fluxos metabólicos pode aumentar o rendimento e o acúmulo de $\mathrm{P} 3 \mathrm{HB}$, assim como a redução da repressão catabólica pode aumentar a produtividade em bioprocessos utilizando xilose e hidrolisados lignocelulósicos.

Palavras-chaves: Sustentabilidade, Biomassa, Hidrolisado hemicelulósico, Plásticos biodegradáveis, Bagaço de cana-de-açúcar, Polihidroxialcanoatos, Análise de fluxo metabólico e Repressão catabólica. 


\begin{abstract}
Lopes MSG. Production of biodegradable plastics using sugarcane bagasse hemicellulosic hydrolysate. 128 p. PhD Thesis (Biotechnology). Instituto de Ciências Biomédicas, Universidade de São Paulo, São Paulo, 2010.
\end{abstract}

Polyhydroxyalkanaotes (PHA), including poly-3-hydroxybutyrate (P3HB) and poly-3hydroxybutyrate-co-3-hydroxyvalerate (PHB-co-3HV), are a family of biodegradable polymers that can be produced using sugarcane bagasse, allowing the its economic competitiveness in comparison to their petrochemical counterpart. Xylose, present in the sugarcane bagasse, can be recovered from hemicellulose by acid hydrolysis more easily and in better yields than can glucose from cellulose. For that reason, the aim of this work is to produce PHA from hemicellulosic hydrolysate of sugarcane bagasse. In a bioprospecting program, Burkholderia sacchari IPT101 (used as control) and Bacillus sp. MA3.3 standed out as producer of P3HB from xylose. Two major points were identified: (i) increase $\mathrm{P} 3 \mathrm{HB}$ productivity $\left(\mathrm{P}_{\mathrm{P} 3 \mathrm{HB}}\right)$, about $40 \%$ lower than in glucose and (ii) reduce glucose catabolite repression. It was proposed that higher specific growth rate could be related with higher sugar consumption rate. However, the overexpression of a key gene of xylose catabolism, xylose isomerase, was not able to increase either xylose consumption or cell growth rate. For that reason, in silico metabolic flux analysis was used to identify key genes of $\mathrm{PH} 3 \mathrm{~B}$ production from xylose. In silico simulations indicated that it was possible to increase $\mathrm{P} 3 \mathrm{HB}$ yields to $0.25 \mathrm{~g} \mathrm{~g}^{-1}$ to $0.38 \mathrm{~g} \mathrm{~g}^{-1}$, that is similar to those of glucose and fructose. For that, three modifications are pointed out: (i) lower fluxes in the tricarboxylic acid cycle (TCA); (ii) higher fluxes through the lower part of the pentose phosphate pathway and (iii) the higher activity of the xylose catabolic enzymes. In bacteria the phosphoenolpyruvate-phosphotransferase system (PTS) is responsible for sugar transportation and regulation of catabolite repression though transcription factors. For Gram negatives bacteria this transcription factor is the complex CRP-cAMP and for Gram positive bacteria is the protein CcpA. Two mutants with catabolite repression released were obtained: B. sacchari PTS Glucose ${ }^{+}$and Bacillus sp. $\Delta$ CcpA. For both, the sugars were consumed simultaneously, resulting in a reduced time to exhaust all sugars in the medium. However, due to a different carbon flux distribution, especially a higher flux through the TCA, biomass and P3HB production decreased. In experiments using sugarcane bagasse hydrolysate, IPT101 and MA3.3 presented inhibit growth. For that reason, a new bioprospecting program screened Burkholderia sp. F24 due its ability to consume all the organics substrates from the hydrolysate and produce PHA. Best results in literature were obtained with $\mathrm{P} 3 \mathrm{HB}$ production from xylose and sugarcane hydrolysate and of PHB-co-3HV using xylose and levulinc acid. In bioreactor experiments in high cell density experiments it was reached $25.04 \mathrm{~g} \mathrm{l}^{-1}$ of biomass, $49.31 \%$ of P3HB accumulation of cell dry weight and $0.28 \mathrm{~g} \mathrm{l}^{-1} \mathrm{~h}^{-1}$ of volumetric productivity. It was demonstrated the possibility to reach even higher cell density with more concentrated hydrolysates. Moreover, it was possible to modulate de molar fraction of 3HV in PHB-3HV synthesis by F24 using xylose and levulinc acid. In the conclusion, redirecting metabolic fluxes can increase yields and $\mathrm{P} 3 \mathrm{HB}$ accumulation, moreover, reduction of catabolite repression can increase productivity in bioprocesses using xylose and lignocellulosic hydrolysates.

Key words: Sutentability, Biomass, Hemicellulosic hydrolysate, Biodegradable plastics, Sugarcane bagasse, Polyhydroxyalkanoates, Xylose, Metabolic flux analysis and Catabolite repression. 


\section{INTRODUÇÃO E JUSTIFICATIVA}

Plásticos são materiais incrivelmente versáteis. São baratos, leves, duráveis, resistentes à corrosão e possuem propriedades de isolamento térmico e elétrico. A diversidade dos polímeros e a versatilidade de suas propriedades são utilizadas em quase todas as atividades industriais, da automobilística à medicina (ANDRADE e NEAL, 2009; REDDY et al., 2003). Polímeros sintéticos são produzidos através da polimerização de monômeros derivados do petróleo ou gás natural, e os plásticos são feitos desses polímeros combinados a vários aditivos químicos.

O primeiro polímero sintético, o baquelite, foi produzido pelo químico belga Leo Baekeland em 1907. Muitos outros foram subsequentemente desenvolvidos durante as décadas seguintes. Entretanto, foi apenas nas décadas de 40 e 50 que se iniciou a produção em massa de produtos plásticos. A produção de plásticos aumentou substancialmente durante os últimos 60 anos, de 0.5 milhão de tonelada em 1950 para 260 milhões de toneladas em 2008 (utilizando cerca de $8 \%$ da produção mundial de petróleo), com a perspectiva de exceder os 300 milhões de toneladas em 2010 (THOMPSON et al., 2009).

Materiais descartáveis e embalagens, que representam um terço do total da produção, causam o maior impacto ambiental devido à dificuldade de descarte. Mais de $90 \%$ do material plástico em aterros sanitários de países desenvolvidos consiste em polietileno, cloreto de polivilina (PVC) e poliestireno, em proporções semelhantes (ATLAS e BARTHA, 1997). Sendo xenobióticos, estes polímeros sintéticos são recalcitrantes à degradação microbiana, devido à falta de aparato enzimático adequado. Além disso, o excessivo peso molecular também parece ser o responsável pela resistência à biodegradação e à sua persistência no ambiente (ATLAS BARTHA, 1997). Por este motivo, nos últimos anos, tem havido uma preocupação sobre os efeitos da má disposição destes materiais no meio ambiente, especialmente nos ambientes aquáticos (REDDY et al., 2003; THOMPSON et al., 2004; THOMPSON et al., 2009;).

Os detritos plásticos são encontrados em todos os habitats marinhos, incluindo os pólos e mares profundos. Além de detritos plásticos grandes, também se encontram fragmentos microscópicos de plásticos $(<20 \mu \mathrm{m})$ sendo que ambos ocasionam sérios problemas para a vida selvagem. Mais de 260 espécies animais são conhecidas por ingerirem ou ficarem emaranhadas em detritos plásticos, sendo que a ingestão de plásticos pode estar amplamente distribuída em certas populações (chegando a 95\% dos indivíduos) comprometendo a alimentação e sobrevivência desses animais. Por outro lado, o emaranhamento por detritos plásticos pode causar ferimentos graves e até a morte para diversas espécies (DERRAIK, 2002; GREGORY 2009). 
A incineração de plásticos tem sido uma opção de gerenciamento de resíduos, já que o plástico possui alto valor calorífico. Mas, além de ser um processo caro, pode ser também perigoso. Dioxinas e furanos podem ser liberadas durante a incineração de certos plásticos (ATLAS e BARTHA, 1997). A reciclagem de materiais vem crescendo nos últimos anos, mas a taxa de reciclagem para a maioria das embalagens plásticas continua baixa (DAVIS e SONG, 2006; HOPEWELL et al. 2009). Existe um número muito grande de tipos de plásticos utilizados em embalagens. Cada um possui aditivos diferentes: compostos de reforços, colorantes e plastificantes (ANDRADY E NEAL, 2009; THOMPSON et al., 2009). A complexa composição destes plásticos, juntamente com a contaminação que usualmente ocorre durante seu uso, torna a reciclagem nãoeconômica em comparação com os aterros sanitários (SONG et al., 2009). Além disso, as modificações das propriedades ocasionadas pela reciclagem podem limitar as suas aplicações posteriores (REDDY et al., 2003). Outro problema que está relacionado com o gerenciamento de resíduos plásticos é o descarte incorreto de lixo nos espaços urbanos e rurais. Este problema vem aumentando em países como a Inglaterra, nos últimos cinco anos (THOMPSON et al. 2009).

Verifica-se, portanto, a existência de uma demanda social e ambiental pela substituição desses materiais por outros mais adequados ao meio ambiente, principalmente por materiais biodegradáveis, aqui também chamados de bioplásticos. Apenas no final da década passada, a Sociedade Americana para Testes e Materiais (ASTM International) - a maior organização de fonte para padrões em materiais, produtos, sistemas e serviços - apresentou uma série de normas para definir degradação e biodegradação de plásticos, conceitos estes adotados nesta tese (norma ASTM 6400). Os plásticos degradáveis são aqueles projetados para sofrer uma mudança significativa em sua estrutura química sob condições ambientais específicas, resultando em perda de algumas propriedades que podem variar conforme medição por testes padrão apropriados. Dentre os plásticos degradáveis, destacam-se os:

- Plástico biodegradável: aquele capaz de ser sujeito à decomposição em dióxido de carbono, metano, água, compostos inorgânicos ou biomassa. $\mathrm{O}$ mecanismo predominante é a ação enzimática de microorganismos, que pode ser medida por testes padronizados em determinado período de tempo, e refletindo a condição de escoamento existente.

- Plástico fotodegradável: um plástico degradável, cuja degradação resulta da ação da luz natural.

- Plástico degradável por oxidação: plástico degradável cuja degradação resulta da oxidação.

Plásticos fotodegradáveis possuem grupos sensíveis à luz, incorporados diretamente na estrutura do polímero como um aditivo. Exposição extensiva à radiação (semanas a meses) pode 
desintegrar a estrutura polimérica, tornando-a mais suscetível à degradação bacteriana. Porém, quando alocados em aterros sanitários não estão expostos à luz. Portanto, não são degradados. Existem também plásticos semi-biodegradáveis nos quais o amido está incorporado a uma poliolefina. Quando descartados, as bactérias degradam o amido. Porém, o polietileno se mantém não degradado. Nos plásticos oxi-degradáveis, incorpora-se um aditivo que potencializa a ação do oxigênio, da temperatura e da radiação ultravioleta, para quebrar o plástico em minúsculos fragmentos. Segundo os fabricantes, este aditivo tornaria o material susceptível à ação dos microrganismos, tornando-o também biodegradável (RESBRASIL, 2010). Estudos recentes contestam esta afirmação (FECHINE et al., 2009). No começo de 2008, o governador José Serra vetou uma proposta de lei que tornaria o uso de aditivos oxi-degradáveis em sacolas plásticas, devido à dúvida dos reais benefícios ao meio ambiente (VASCONCELOS, 2008).

Uma vez que a biodegradabilidade do material tenha sido demonstrada, sua aplicação deve ser cuidadosamente escolhida. É necessário ter em mente que uma das propriedades mais interessantes dos plásticos convencionais é precisamente a sua capacidade de resistir às intempéries. Se o produto final é desenhado para resistir às intempéries (partes externas de veículos ou fios elétricos, por exemplo), a biodegradabilidade deve ser evitada. Claramente, então, biodegradabilidade é vantajosa quando é implicitamente demandada. Dessa maneira, as resinas convencionais ainda são indispensáveis e diferentes procedimentos de descartes são necessários para cada caso.

Na Tabela 1, são descritas as principais classes de polímeros biodegradáveis já produzidos em escala comercial ou piloto (PRADELLA et al., 2006). É interessante apontar que, da mesma forma que há plásticos que são produzidos pela síntese de monômeros derivados do refino do petróleo com certo grau de biodegradabilidade (SONG et al., 2009), como as poliuretanas, existem também bioplásticos de origem microbiana que não biodegradáveis, como os politioésteres (STEINBÜCHEL, 2005). 
Tabela 1 - Principais classes de bioplásticos produzidas em escala piloto ou comercial.

\begin{tabular}{|c|c|c|c|}
\hline Bioplástico & Marca - Empresa & Tipo de polímero & Estrutura/Método de produção \\
\hline 1. Polímero de amido & & Polissacarídeo & Polímero natural modificado \\
\hline 2. Polilactatos (PLA) & Nature Works - Cargill & Poliéster & $\begin{array}{l}\text { Ácido láctico produzido por fermentação } \\
\text { seguido de polimerização }\end{array}$ \\
\hline 3. Polihidroxialcanoatos (PHA) & & Poliéster & Bioconversão direta de fonte de carbono por \\
\hline PHB-co-3HV & Biopol - Metabolix & & microrganismos ou em vegetais geneticamente \\
\hline PHB-HA ${ }_{M C L}$ & Nodax - Procter \& Gamble & & modificados. \\
\hline $\begin{array}{l}\text { 4. Poliésteres alifáticos - } \\
\text { aromáticos }\end{array}$ & & Poliéster & 1-3 propanodiol produzido por fermentação \\
\hline Politrimetilenotereftalato & $\begin{array}{l}\text { Sorona - Dupont } \\
\text { Coterra - Shell }\end{array}$ & & $\begin{array}{l}\text { seguido de copolimerização com ácido } \\
\text { tereftálico ou dimetil tereftalato. }\end{array}$ \\
\hline Polibutilenotereftalato & $\begin{array}{l}\text { Biomax - Dupont } \\
\text { EastarBio - Eastar } \\
\text { Ecoflex - Basf }\end{array}$ & & $\begin{array}{l}\text { 1-4 butanodiol produzido por fermentação } \\
\text { seguido de copolimerização com ácido } \\
\text { tereftálico }\end{array}$ \\
\hline Polibutilenosuccinato & $\begin{array}{l}\text { Bionolle 1000- Showa } \\
\text { Mitsubishi, Ajinomoto }\end{array}$ & & $\begin{array}{l}\text { 1-4 butanodiol copolimerizado com ácido } \\
\text { succínico, ambos produzidos por fermentação }\end{array}$ \\
\hline 5. Poliuretanas & & Poliuretano & $\begin{array}{l}\text { Polimerização de poliois obtidos por } \\
\text { fermentação ou purificação química com } \\
\text { isocianatos petroquímico }\end{array}$ \\
\hline 6. Nylon & & Poligamia & \\
\hline Nylon 6 & Nylon 6 - DSM & & $\begin{array}{l}\text { Condensação da caprolactama produzida por } \\
\text { fermentação }\end{array}$ \\
\hline Nylon 6.6 & & & $\begin{array}{l}\text { Ácido adípico produzido por fermentação } \\
\text { seguido por copolimerização com } \\
\text { hexametilenodiamina }\end{array}$ \\
\hline Nylon 69 & & & $\begin{array}{l}\text { Monômero obtido por transformação } \\
\text { química do ácido oléico }\end{array}$ \\
\hline
\end{tabular}

FONTE: adaptado de PRADELLA, 2006

Classificam-se os polímeros de acordo com a sua matéria-prima: renováveis (base verde) e não renováveis (base petroquímica). Porém, muitos dos plásticos biodegradáveis comerciais hoje apresentam formulações que combinam ambas as classes, para reduzir custos e/ou melhorar o desempenho (CHEN 2009), como poliésteres alifáticos-aromáticos e nylon (Tabela 1). Atualmente no Brasil, são produzidos pela Braskem polietilenos não biodegradáveis, a partir de cana-deaçúcar.

Dentre os bioplásticos produzidos de fontes renováveis, destacam-se pelas suas propriedades os PHA e os polilactatos (PLA). Os PHA são termoplásticos naturais que ocorrem numa grande gama de bactérias, enquanto o PLA é produzido através da polimerização do ácido lático oriundo da fermentação. Porém, como demonstrado na Tabela 2, a família PHA contém características mais apropriadas que tornam sua produção mais vantajosa tanto a curto, como a médio e longo prazos.

Os PHA podem ser acumulados em grande quantidade sem afetar a pressão osmótica das células, chegando a participar de até $80 \%$ do peso seco celular (KAHAR et al., 2003). Os grânulos de PHA são formados quando há limitação de um ou mais elementos essenciais ao crescimento bacteriano, como nitrogênio, fósforo, magnésio ou oxigênio. São usados como fontes de energia e 
de carbono, quando esses elementos voltam a ser disponíveis. O PHA mais estudado e mais comum entre as bactérias é o homopolímero de polihidroxibutirato (P3HB) que é sintetizado a partir de acetil-CoA obtido do catabolismo de carboidratos, envolvendo a ação de três enzimas (OEDING e SCHLEGEL, 1973; SENIOR e DAWES, 1973). Primeiro, por ação da 3-cetotiolase, duas moléculas de acetil-CoA se condensam, gerando acetoacetil-CoA. Esta, em seguida, sofre uma redução, formando $(R)$-3-hidroxibutiril-CoA por ação da acetoacetil-CoA redutase. A PHA sintase, finalmente, incorpora cada molécula de $(R)$-3-hidroxibutiril-CoA (3HB) à cadeia polimérica em crescimento.

Tabela 2 - Comparação entre polilactatos (PLA) polihidroxialcanoatos (PHA).

\begin{tabular}{|c|c|c|}
\hline PLA vs. PHA & PLA & PHA \\
\hline Estrutura do monômero & Apenas D- e L-ácido lático (AL) & Pelo menos 130 monômeros \\
\hline Custo de produção & $\begin{array}{l}\text { Comparável com os dos plásticos convencionais } \\
\text { como o PET }\end{array}$ & Pelo menos $2 \mathrm{x}$ o do PLA \\
\hline Propriedades do material & $\begin{array}{l}\text { Pobre, pode ser ajustada regulando a proporção } \\
\text { de } D \text { e } L \text {-AL }\end{array}$ & De rígido, flexível a elástico, completamente controlável \\
\hline Maturidade tecnológica & $\begin{array}{l}\text { A produção de AL está estabelecida, porém a } \\
\text { polimerização a PLA é complicada. Apenas uma } \\
\text { companhia, NatureWorks, produz PLA em } \\
\text { grande escala. }\end{array}$ & $\begin{array}{l}\text { Ao menos } 10 \text { companhias no mundo estão produzindo } \\
\text { PHA em escala maior que } 2000 \text { t por ano via } \\
\text { fermentação microbiana. }\end{array}$ \\
\hline Investimento & $\begin{array}{l}\text { Grande investimento em capital fixo: Nature } \\
\text { Works investiu } 1 \text { bilhão U\$S nos últimos anos } \\
\text { em uma planta de } 140000 \text { ton por ano. }\end{array}$ & $\begin{array}{l}\text { Pequeno investimento: plantas atuais de fermentação } \\
\text { microbiana aeróbica podem ser utilizadas para a } \\
\text { produção de PHA. }\end{array}$ \\
\hline Propriedade intelectual & $\begin{array}{l}\text { Coberta na maioria das áreas de aplicação e } \\
\text { produção }\end{array}$ & Muito espaço para exploração \\
\hline Áreas de aplicação & $\begin{array}{l}\text { Embalagens, implantes médicos, impressão, } \\
\text { vestuário e etc. Ainda limitado pela temperatura } \\
\text { de transição vítrea de } 65 \text { a } 75^{\circ} \mathrm{C} \text { para baratos } \mathrm{P}(L \text { - } \\
\text { LA). }\end{array}$ & $\begin{array}{l}\text { Para quase todas as áreas da indústria de plástico } \\
\text { convencional, limitado apenas no alto custo atual. }\end{array}$ \\
\hline
\end{tabular}

FONTE: adaptado de CHEN, 2009

Na presença de um co-substrato, como o propionato, um ácido graxo de cadeia ímpar, uma molécula de propionil-CoA poderá produzir o monômero $(R)$-3-hidroxivaleril-CoA. Dessa maneira, a PHA sintase, incorpora tanto moléculas de $(R)$-3-hidroxivaleril-CoA (3HV) como de $(R)$-3-hidroxibutiril-CoA à cadeia polimérica em crescimento, para formar o copolímero poli-3hidroxibutirato-co-3-hidroxivalerato $\mathrm{P}(\mathrm{HB}-c o-3 \mathrm{HV})$. Além dos monômeros $(R)$-3-hidroxibutirilCoA (3HB) e (R)-3-hidroxivaleril-CoA (3HV), cerca de 130 monômeros diferentes já foram identificados como constituintes de PHA produzidos por bactérias, a partir de diversas fontes de carbono (STEINBÜCHEL e VALENTIN, 1995) que são subdivididos em dois grandes grupos: (i) de cadeia curta $\left(\mathrm{PHA}_{\mathrm{SCL}}\right.$ - hydroxyacids of short-chain-length), contendo de 3 a 5 átomos de carbono na cadeia principal; e (ii) de cadeia média $\left(\mathrm{PHA}_{\mathrm{MCL}}\right.$ - hydroxyacids of medium-chainlength), contendo de 6 a 14 átomos de carbono na cadeia principal. Apesar dos PHA e do PLA constituírem classes de polímeros diferentes, hoje já são produzidos, por E. coli recombinantes, copolímeros de poli-3-hidroxibutirato-co-lactato (JUNG et al., 2010). 
É interessante apontar que as empresas que hoje produzem PHA em escala piloto ou industrial utilizam glicose ou sacarose para a produção de $\mathrm{P} 3 \mathrm{HB}$, ácido propiônico para produção

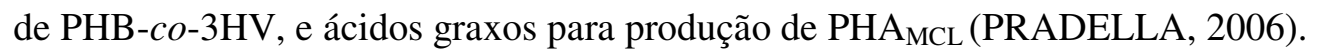

Existem claras vantagens ambientais em processos renováveis, porém, aqueles que têm como base a agricultuta implicam em diversos problemas ambientais. Erosão do solo, perda de biodiversidade, uso da terra e consumo de água são alguns dos aspectos não vantajosos para a indústria de processos verde. Usar alimentos para a produção de biocombustíveis ou energia têm sido debatido em âmbito moral. Em um nível mais amplo, este debate se caracteriza pela discussão de uso da terra. Em um planeta em que a terra é limitada e a população crescente, a principal discussão é como a terra deve ser utilizada: para produção de comida, para a produção de combustíveis, urbanização etc. Ao nível de políticas públicas, mais especificamente da Política Nacional do Meio Ambiente, a regulação da gestão dos recursos ambientais, inclusive o uso e ocupação do solo, dá-se pela implementação do Zoneamento Ambiental.

Outra questão importante é saber se o bioproduto utiliza consideráveis porções de combustíveis fósseis e energia, na produção da matéria-prima e no seu processo. Uma análise da sustentabilidade do processo, portanto, é necessária para avaliar caso a caso. De outra forma, a troca de processos de base petroquímica para processos de base verde em grande escala, apenas trocaria um conjunto de problemas ambientais por outros.

Uma ferramenta de análise de sustentabilidade que leva em conta desde a produção da matéria-prima até o descarte do produto é a análise de ciclo de vida do produto. Utilizando parcialmente esta metodologia, HARDING et al. (2007) comparou a produção de matéria-prima e processo de produção de $\mathrm{P} 3 \mathrm{HB}$, polipropileno e polietileno de alta e baixa densidade. Porém não analisou os impactos de uso, reuso e descarte. $\mathrm{O}$ autor descreve que em quase todas as categorias analisadas (que incluem energia necessária, aquecimento global, depleção abiótica e toxicidade terrestre e de águas doce e salgada), a produção de P3HB a partir de sacarose alcançou reduções significantes. Por outro lado, devido à utilização de fertilizantes na agricultura, ácidos e um número significante de sais, a produção de P3HB aumenta o nível potencial de toxicidade das águas residuais e de eutrofização. Porém, conclue-se que o processo de produção de P3HB é mais benéfico ao meio ambiente do que os de polipropileno e poliestireno.

A mudança do clima é um dos mais graves problemas ambientais enfrentados nos últimos anos, podendo ser considerada uma das mais sérias ameaças à sustentabilidade do meio ambiente, à saúde, e ao bem-estar humano e à economia global. Após a Revolução Industrial, o uso de combustíveis fósseis nos meios de produção elevou em quase $50 \%$ os níveis de concentração de gases poluentes, entre eles os chamados gases de efeito estufa. Os gases de efeito estufa têm a 
capacidade de reter calor e alterar tanto o equilíbrio térmico quanto o climático do planeta (IPCC, 2001). A redução dos gases de efeito estufa é uma das metas do Protocolo de Kyoto, acordo assinado em 1997, pelos países participantes da Convenção-Quadro das Nações Unidas sobre Mudanças Climáticas. Ele passou a vigorar em fevereiro de 2005. Uma das linhas de projetos para mitigação do efeito estufa é a redução de emissões, por meio do aumento da eficiência energética e do uso de fontes renováveis de energia, conhecidos como projetos de energia. Neste sentido, enquadram-se processos de produção de plásticos a partir de fontes renováveis. Yu e CHEN (2009) concluem que a substituição dos similares petroquímicos por PHA pode reduzir em até $80 \%$ a emissão de gases de efeito estufa.

Dentro deste cenário de processos de base verde, destaca-se o modelo brasileiro de biorrefinarias de cana-de-açúcar, no qual se desenvolveu um dos sistemas (talvez "o sistema") mais eficiente do planeta para produção de matérias-primas renováveis para a produção de combustíveis, polímeros e outros materiais. De acordo com a Agência Norte-Americana de Proteção Ambiental (EPA), o etanol brasileiro de cana-de-açúcar reduz as emissões de gases de efeito estufa (GEE) em $61 \%$ em relação à gasolina - o que o caracteriza como um "biocombustível avançado" (FAPESP, 2010). A literatura atual identifica três níveis de biorrefinarias: biorrefinaria de fase I seria uma usina padrão produtora de etanol, que utiliza certa quantidade de cana-de-açúcar para produzir determinada quantidade de etanol. Esta quase não possui quase nenhuma flexibilidade de processo, que se dá apenas pela proporção de etanol e açúcar produzidos. A integração da produção de P3HB a partir de sacarose, ou de polietileno a partir de etanol caracterizaria uma biorrefinaria de fase II. Essa nova planta aumenta o número de possibilidades de conectar novas linhas de produtos industriais com a já existente unidade de produção. Uma biorrefinaria de fase III não só produz uma variedade de combustíveis, químicos, intermediários e produtos finais, mas também utiliza várias fontes de matérias-primas e processos (KAMM e KAMM, 2004). A flexibilidade de uso de suas matérias-primas é o fator primordial para a adaptabilidade diante das mudanças na demanda para suprir commodities alimentícias e industriais, destacando o uso de resíduos lignocelulósicos (revisado por KAMM et al., 2006). Neste cenário, a produção de PHA integrada a uma usina de cana-de-açúcar torna-se interessante devido à capacidade do sistema de suprir a energia necessária para o processo, disponibilidade de substratos para a produção e produtos para a etapa de purificação, e também pela habilidade do sistema de processar e utilizar os seus efluentes (NONATO et al., 2001). Além disso, como todo carbono envolvido (tanto combustível quanto de matéria-prima) é originado da cana-de-açúcar, as emissões de $\mathrm{CO}_{2}$ pela planta de produção também retornam para os campos de cultivo através da fotossíntese, o balanço de emissão de carbono é perto do zero (NONATO et al., 2001) . 
Recentemente, foi desenvolvido pelo IPT, em cooperação com o Centro Tecnológico da Copersucar e a Universidade de São Paulo, com o apoio do PADCT-Finep, um processo para a produção de poli-3-hidroxibutirato (P3HB) e de seu copolímero poli-3-hidroxibutirato-co-3hidroxivalerato (P3HB-co-3HV) (NONATO et al., 2001). Esse processo foi transferido para a empresa P3HB Industrial S/A, que atualmente produz cerca de 50 toneladas anuais desses materiais utilizando caldo de cana-de-açúcar (sacarose) como substrato. NONATO e colaboradores (2001) estimaram os custos de produção da planta de produção de 10.000 toneladas de P3HB ao ano, integrada a uma usina de etanol e açúcar no interior do Estado de São Paulo. A composição dos custos representa 29\% em relação a matéria-prima (sacarose), 20\% com produtos químicos, $27 \%$ com depreciação dos equipamentos, $11 \%$ com gastos com energia e $13 \%$ com outros gastos não especificados. Dessa maneira, verifica-se que na produção de biopolímeros, mesmo dentro de um sistema eficiente de produção de açúcar, o custo da matéria-prima ainda é o mais representativo.

Os PHA têm sido comercializados atualmente ao preço médio da ordem de US\$ 4,00 / kg, muito menor que os US\$ 10 a US\$15/kg praticados nas décadas de 80 e 90, mas ainda assim, superior ao polipropileno comercializado hoje a cerca de US\$ 1,5/kg (PRADELLA 2006). A expectativa inicial (nos anos 90) de que o mercado pagaria um prêmio extra pelo produto por suas características de biodegradabilidade não tem se cumprido (PRADELLA, 2006). Dessa maneira, o desafio atual para os bioplásticos é a redução dos custos ao mesmo nível dos congêneres produzidos, a partir de petróleo. Neste sentido, os seguintes objetivos devem ser seguidos (PRADELLA, 2005; CHEN 2009): (i) uso de resíduos de baixo custo como fonte de carbono, (ii) aumento do rendimento e da produtividade do bioprocesso e a (iii) modulação da composição dos polímeros para ampliação de suas aplicações.

No sentido de utilizar resíduos de baixo custo, subprodutos da agricultura são os recursos renováveis baratos e virtualmente inesgotáveis, uma vez que a sua formação tem como base o processo fotossintético e a atividade antrópica. Para uso destes materiais lignocelulósicos em processos biológicos, há primeiramente necessidade da liberação da celulose e da hemicelulose do complexo formado com a lignina, seguido da quebra dos polímeros de açúcar, obtendo desta forma, pentoses e hexoses livres para o processo de conversão microbiana ao produto desejado (CHANDRAKANT e BISARIA, 1998; LEE, 1997).

Os principais métodos de hidrólise são aqueles catalisados por ácidos ou enzimas celulolíticas (MARTIN et al., 2002). A hidrólise enzimática depende de um pré-tratamento brando para hidrólise da hemicelulose e, posteriormente, de enzimas para quebrar a celulose. Estas enzimas representam um custo significante e limitante para o processo atualmente. Enquanto os 
trabalhos na literatura se concentram na liberação da glicose proveniente da celulose para os bioprocessos, os açúcares provenientes da hemicelulose, principalmente a xilose, podem ser mais facilmente recuperados e com melhores rendimentos através da hidrólise branda da hemicelulose.

Hoje, 400 usinas concentradas principalmente no Estado de São Paulo processam cerca de 600 milhões de toneladas cana-de-açúcar, produzindo um montante de 200 milhões de toneladas de bagaço. Uma parte desse bagaço é queimado para geração de energia. Porém, em um modelo de biorrefinaria de fase III, o bagaço de cana-de-açúcar poderia ser utilizado como matéria-prima nobre para a produção de diversos produtos (revisado por KAMM et al., 2006).

É importante destacar que o bagaço apresenta-se como o resíduo lignocelulósico mais susceptível à pré-hidrólise hemicelulósica dentre aqueles estudados na literatura (MARTIN et al., 2007). Além disso, o uso do bagaço como matéria para a produção de biopolímeros não depende do aumento da fronteira agrícola ou substituição de culturas alimentícias. Pelo contrário aumentaria a sustentabilidade ambiental, econômica e social da indústria sucroalcooleira, favorecendo a competitividade de seus produtos.

O pré-tratamento ácido do bagaço, que libera principalmente a hemicelulose e lignina, pode ser utilizado tanto para produzir PHA como outros produtos, como xilitol. Posteriormente, a celulose residual pode ser hidrolisada para produzir etanol, ou outros produtos de fermentação como ácido lático, butanol e acetona (KAMM et al., 2006). Outros derivados por síntese química podem ser produzidos, a partir de bagaço de cana-de-açúcar. Ácido levulínico, por exemplo, utilizado como precursor de polímeros ou flavorizante, pode ser formado a partir da hidrólise catalisada por ácidos $\left(4.45 \%\right.$ de $\mathrm{HCl}$ a $220{ }^{\circ} \mathrm{C}$ por $\left.45 \mathrm{~min}\right)$ do bagaço de cana com rendimento de cerca 23\% (YAN et al., 2008). Ácido levulínico também pode ser utilizado como precursor de unidade 3-hidroxivaleril-CoA para a produção do copolímero PHB-co-3HV (ANEXO V; CHUNG et al., 2001; KEENAN et al.,2006). KEENAN e colaboradores (2004) demonstraram que seria possível variar de 0 a $60 \%$ o conteúdo molar de unidade $3 \mathrm{HV}$, variando a concentração deste ácido do meio de cultura com xilose(de 0 a $6 \mathrm{~g} \mathrm{l}^{-1}$ ), controlando, assim, as propriedades do polímero formado. Além do mais, os rendimentos de produção de unidade $3 \mathrm{HV}$ estão em torno de $0.5 \mathrm{~g}$ por g ácido levulínico consumido. Eles são relativamente altos em comparação com aqueles obtidos pelo ácido propiônico (0.02-0.13 $\mathrm{g} \mathrm{g}^{-1}$ ) (GOMEZ et al., 1996). Em adição aos melhores rendimentos, a produção de ácido levulínico em biorrefinarias potencialmente reduzirá o seu custo favorecendo a produção econômica de PHA (BOZELL et al., 2000).

Finalmente, o pré-tratamento de materiais lignocelulósicos libera uma porção de compostos inibitórios para o crescimento de microrganismos. Além das vantagens demonstradas da produção de PHA a partir de materiais lignocelulósicos, o processo de produção de PHA, a partir do pré- 
tratamento do bagaço de cana torna-se interessante ao se comparar com outros bioprocessos já que se pretende realizá-lo em aerobiose, aumentando a possibilidade da "destoxificação" simultânea de compostos tóxicos liberados durante a hidrólise da hemicelulose via oxidação biológica, tornando o processo mais atraente economicamente.

Resumindo esta introdução: verifica-se uma demanda da sociedade por plásticos biodegradáveis com aplicação relacionada com o descarte rápido de materiais plásticos. Dentre os polímeros biodegradáveis atuais, destacam-se os polihidroxialcanoatos por serem produzidos por fontes renováveis e estudos de sustentabilidade demonstrarem os seus benefícios para o meio ambiente em relação aos plásticos petroquímicos, principalmente em relação à emissão de gases de efeito estufa. Por fim, o modelo de produção de PHA utilizando bagaço de cana-de-açúcar integrado a usinas sucroalcooleiras representa uma possibilidade de viabilizar a competitividade de PHA em relação aos congêneres petroquímicos. 


\section{Conclusões}

1. O isolamento de linhagens mostrou-se como poderosa ferramenta para obter novos microrganismos de relevância biotecnológica. Neste trabalho, foi demonstrada a possibilidade de utilizar a biodiversidade microbiana para superar obstáculos impostos a linhagens-modelo como Bacillus subtilis ou Escherichia coli relacionados com: (i) a produção de PHA, (ii) o consumo de xilose e (iii) a utilização dos compostos inibitórios e (iv) a produção em altas densidades celulares. A linhagem Burkholderia sp. F24 mostrou-se robusta para futuros experimentos de produção de PHA a partir de hidrolisado hemicelulósicos em altas densidades celulares ou empregando técnicas de engenharia metabólica.

2. Através da análise das reações gerais de produção de $\mathrm{P} 3 \mathrm{HB}$, foi verificada uma diferença entre os balanços energéticos da produção de $\mathrm{P} 3 \mathrm{HB}$, a partir de xilose e glicose. $\mathrm{O}$ fator de conversão teórico de síntese de ATP é $5.8 \mathrm{~mol} \mathrm{~mol}^{-1}$ (ATP/ 3HB) em xilose, inferior ao valor produzido pelo metabolismo de glicose $\left(7 \mathrm{~mol} \mathrm{~mol}^{-1}\right)$. Mais de $80 \%$ da diferença entre os dois balanços é devido à diferença entre os mecanismos de assimilição e fosforilação destes açúcares.

3. A obtenção de mutantes com repressão catabólica (parcialmente ou completamente) abolida pode diminuir o tempo de consumo dos açúcares, aumentando assim a velocidade de crescimento e produtividade. Modificações genéticas devem ser feitas, levando-se em conta efeitos adversos. A deleção do sistema (ou partes do) PTS parece não ser um bom alvo em espécies de Burkholderia, apesar de resultados positivos em linhagens de E. coli. O PTS apresenta-se como um sistema eficiente no transporte de açúcares além de controlar importantes nódulos dos fluxos metabólicos. A deleção de reguladores globais de transcrição, como o CcpA, também implicam em impactos em diferentes pontos de regulação e funções celulares.

4. Apesar de trabalhos encontrados na literatura indicarem que a xilose isomerase é um gene-chave para aumentar a velocidade de consumo de xilose, o aumento da atividade enzimática da xilose isomerase não apresentou efeito positivo na produção de PHA em $B$. sacchari. Por outro lado a análise do metabolismo in silico apresentou-se como ferramenta eficiente para a identificação de genes-chave para o aumento de rendimento e acúmulo de PHA. As modificações do metabolismo indicadas pela análise de fluxo são: (i) aumento no fluxo na parte inferior da via das pentoses ; (ii) aumento na atividade das enzimas de catabolismo de xilose e (iii) redução do fluxo do ciclo do ácido tricarboxílico (TCA). 
5. Através da análise da expressão de genes, modelos de fluxos metabólicos in silico e experimentos com mutantes com repressão catabólica foi possível identificar proteínas-chave que controlam diferentes níveis do sistema celular, como a transaldolase, TalA e regulador global de transcrição $\mathrm{Crp} *$ independente de AMPc. Através da ação conjunta destas proteínas, pretende-se liberar os mecanismos de repressão catabólica e alcançar as mudanças de fluxos propostas no item anterior. Estas proteínas se mostram importantes não só para a produção de PHA, mas também de outros produtos, a partir de xilose e hidrolisados hemicelulósicos, como etanol e xilitol.

6. Foram demonstradas algumas vantagens de um processo aeróbio de produção de PHA para utilização de hidrolisados hemicelulósicos. Primeiro, Burkholderia sp. F24 foi capaz de simultaneamente destoxificar e produzir PHA utilizando o hidrolisado de bagaço de cana-deaçúcar. Segundo, foram obtidos melhores rendimentos de ATP em comparação com processos anaeróbios de produção de produção etanol. Enquanto a síntese de produção de PHA a partir de xilose pode gerar $85 \%$ do rendimento de ATP em relação ao mesmo processo com glicose, a produção de etanol a partir de xilose, por exemplo, não chega a 35\% do rendimento de ATP em comparação com o mesmo processo utilizando glicose.

7. O hidrolisado hemicelulósico de bagaço de cana-de-açúcar apresentou-se como uma matériaprima alternativa com grande potencial para a produção de P3HB e PHB-co-3HV. Foram obtidos os melhores resultados de destaque na literatura para a produção de P3HB e PHB-co-3HV, a partir de xilose e ácido levulínico, além dos melhores resultados de produção de P3HB utilizando hidrolisados hemicelulósicos. Pela primeira vez, foram obtidos resultados em altas densidades celulares para a produção de PHA utilizando hidrolisados lignocelulósicos: $25.04 \mathrm{~g} \mathrm{l}^{-1}$ de biomassa, $49.31 \%$ de acúmulo de P3HB na massa seca celular e uma produtividade volumétrica de $0.28 \mathrm{~g} \mathrm{l}^{-1}$ $\mathrm{h}^{-1}$. Este valor de produtividade é cerca de duas vezes maior do que o melhor resultado descrito na literatura. 


\section{REFERÊNCIAS BIBLIOGRÁFICAS}

ALtintAS, M. M.; EDDY, C. K.; ZHANG, M.; MCMILlAN, J. D.; KOMPALA, D. S. Kinetic modeling to optimize pentose fermentation in Zymomonas mobilis. Biotech. Bioeng., vol.94, p. 273-295, 2006.

ANDRADY, A. L.; NEAL, M. A. Applications and societal benefits of plastics. Philos. Trans. R. Soc. B. v.364, p.1977-1984, 2009.

ASTM D6400 - 04 Standard specification for compostable plastics. Disponível em: http://www.astm.org/ Standards/D6400.htm. Acesso em: 2 fev. 2010.

ATLAS, R M; BARTHA, R. Microbial ecology: fundamentals and applications. 3 ed. Oxford: Benjamin Cummings, 1997, $640 \mathrm{p}$.

BÁEZ-VIVEIROS, J.L.; OSUNA, J.; HERNÁNDEZ-CHAVEZ, G.; SOBERÓN, X.; BOLÍVAR, F.; GOSSET, G. Metabolic engineering and protein directed evolution increase the yield of $L$-phenylalanine synthesized from glucose in Escherichia coli. Biotech. Bioeng., v. 87, p.516-524, 2004

BAILEY, J. E. Toward a science of metabolic engineering. Science, 252: 1668-1674, 1991.

BAPTIST, J. N. Process for preparing poly-ß)-hydroxybutyric acid. US Patent Application 3036959, 1962a.

BARABOTE, R. D.; SAIER, M. H. Jr. Comparative genomic analyses of the bacterial phosphotransferase system. Microbil. Mol. Biol. Rev. v.69, p.608-634, 2005.

BAUER, K.; BASSAT, A. B.; DAWSON, M.; PUENTE, V. T. D. L.; NEWAY, J. O. Improved expression of human interleukin-2 in high-cell-densityfermentor cultures of Escherichia coli K-12 by a phosphotransacetylasemutant. Appl. Environ. Microbiol., v.56, p.1296-1302, 1990.

BERTRAND, J.; RAMSAY, J.; RAMSAY, B. A.; CHAVARIE C. Biosynthesis of poly- $\beta$-hydroxyalkanoates from pentoses by Pseudamonas pseudoflava. Appl. Envirom. Microbiol., v.56, p.3133-3138, 1999.

BETTENBROCK, K.; SAUERM T.; JAHREIS, K.; KREMLING, A.; JAHREIS, K.; SAUTER, T.; GILLES, E.D. Correlation between growth rates, EIIA ${ }^{\mathrm{Crr}}$ phosphorylation, and intracellular cyclic AMP levels in Escherichia coli $\mathrm{K}-$ 12. J. Bacteriol., v.189, p.6891-6900, 2007.

BETTENBROCK, K.; FICHER, S.; KREMLING, A.; JAHREIS, K.; SAUTER, T.; GILLES, E.D. A quantitative approach to catabolite repression in Escherichia coli. J. Biol. Chem., v.281, p.2578-2584, 2006.

BOTHAST, R. J.; NICHOLS N. N.; DIEN, D. S. Fermentations with new recombinant organisms. Biotechnol. Prog., v.15, p.867 -875, 1999.

BOZELL, J. J.; MOENS, L.; ELliOT D. C.; WANG, Y.; NEUENSWANDER, G. G.; FITZPATRICK, S. W.: BILSKI, R. J.; JARNEFELD, J. L. Production of levulinic acid and use as a platform chemical for derived products. Resour. Conserv. Recycl., v.28, p.227-239, 2000.

BOWIEN, B.; KUSIAN, B. Genetics and control of CO2 assimilation in the chemoautotroph Ralstonia eutropha. Arch. Microbiol., v.178, p.85-93, 2002.

BUCHOLZ, B.; NORDSIEK, G.; MEISTER, M.; BOWIEN B. Transfer of genes from Pseudomonas saccharophila to construct xylose-utilizing strain of Alcaligenes eutrophus. Curr. Microbiol., v.29, p.157-162, 1994.

CARVAlHO, S.; SILVA, S. S.; COVERTI, A.; VITOLO, M. Metabolic behavior of immobilized Candida guilliermondi cells during batch xylitol production from sugarcane bagasse acid hydrolysate. Biotechno. Bioeng., v.79, p.165-169, 2002.

CHANDRAKANT, P; BISARIA, V.S. Simultaneous bioconversion of cellulose and hemicellulose to ethanol. Crit. Rev. Biotechnol., v.18, p.295-331, 1998.

CHEN, G. Q. A microbial polyhydroxyalkanoates (PHA) based bio- and materials industry. Chem. Soc. Rev., v.38, p.2434-2446, 2009. 
CHEN, G. Q.; WU, Q. The application of polyhydroxyalkanoates as tissue engineering materials. Biomaterials. v.26, p.6565-6578, 2005.

CHOI, J.; LEE, S. Y. Process analysis and economic evaluation for poly(3-hydroxybutyrate) production by fermentation. Bioprocess Eng., v.17, p.335-342, 1997.

CHOU, C. H.; BENNETT, G. H.; SAN, K. Y. Effect of modified glucose uptake using genetic engineering techniques on high-level recombinant protein production in Escherichia coli dense cultures. Biotechnol. Bioeng., v.44, p.952960, 1994.

CHUNG, S. H.; CHOI, G. G.; KIM, H. W.; RHEE, Y. H. Effect of levulinic acid on the production of poly(3hydroxybutyrate-co-3-hydroxyvalerate) by Ralstonia eutropha KHB-8862. J. Microbiol., v.39, p.79-82, 2001.

CIRINO, P. C.; CHIN, J. W.; INGRAM, L. O. Engineering Escherichia coli for xylitol production from glucosexylose mixtures. Biotech. Bioeng., v.95, p.1167-1176, 2006.

COLliER, D. N.; HAGER, P. W.; PHIBBS, P. V. Jr. Catabolite repression control in the Pseudomonads. Res. Microbiol., v.147, p.551-561, 1996.

DAVIS, G.; SONG, J. H. Biodegradable packaging based on raw materials from crops and their impact on waste management. Ind. Crop. Prod., v.23, p.147-161, 2006.

DE ANDA, R.; LARA, A. R.; HERNÁNDEZ, V.; HERNÁNDEZ-MONTALVO, V.; GOSSET, G.; BOLIVAR, F.; RAMIREZ, O. Replacement of the glucose phosphotransferase transport system by galactose permease reduces acetate accumulation and improves process performance of Escherichia coli for recombinant protein production without impairment of growth rate. Metab. Eng., v.8, p.281-290, 2006.

DE KONING, G. J. M.; KELLERHALS, M.; VAN MEURS, C.; WITHOLT, B. A process for the recovery of poly(3hydroxyalkanoates) from Pseudomonas 2. Process development and economic evaluation. Bioprocess Eng., v.17, p.15-21, 1997.

DERRAIK, J. G. B. The pollution of the marine environment by plastic debris: a review. Mar. Pollut. Bull., v.44, p.842-852, 2002.

DEUTSCHER, J.; FRANCKE, C.; POSTMA, P. W. How phosphotransferase system-related protein phosphorylation regulates carbohydrate metabolism in bacteria. Microbiol. Mol. Biol. Rev., v.70, p.939-1031, 2006.

DIEN, B.S.; ITEN L.B.; BOTHAST, R.J. Recombinant Escherichia coli engineered for production of L-latic acid. J. Ind. Microbiol. Biotechnol., v.29, p.221-227, 2001.

DJORDJEVIC, G M.; TCHIEU, J. H.; SAIER, M. H. Jr. Genes involved in control of galactose uptake in Lactobacillus brevis and reconstitution of the regulatory system in Bacillus subtilis. J. Bacteriol., v.183, p.3224-3236, 2001.

DUROT, M.; BOURGUIGNON, P. Y.; SCHACHTER, V. Genome-scale models of bacterial metabolism: reconstruction and applications. FEMS Microbiol. Rev., v.33, p.164-190, 2009.

EPPLER, T.; BOOS, W. Glycerol-3-phosphate-mediated repression of malT in Escherichia coli does not require metabolism, depends on enzyme IIAGlc and is mediated by cAMP levels. Mol. Microbiol., v.33, p.1221-1231, 1999.

FAIRES, N.; TOBISCH, S., BACHEM, S., MARTIN-VERSTRAETE, I., HECKER, M., STÜLKE, J. The catabolite control protein CcpA controls ammonium assimilation in Bacillus subtilis. J. Mol. Microbiol. Biotechnol., v.1, p.141148, 1999.

FAPESP. Pesquisar para exportar. Disponível em: <http://www.agencia.fapesp.br/materia/11731/ especiais/pesquisar-para-exportar.htm>. Acesso em: 10 jan. 2010.

FELIPE, M. G. A.; VITOLO, M.; MANCILHA, I. M.; SILVA, S. S. Environmental parameters affecting xylitol production form sugar cane bagasse hemicellulosic hydrolisate by Candida quilliermondii. J. Ind. Microbiol. Biotechnol., v.18, p.251-254, 1997. 
FLORES, N.; XIAO, J.; BERRY, A.; BOLIVAR, F.; VALLE, F. Pathway engineering for the production of aromatic compounds in Escherichia coli. Nat. Biotechnol. v.14, p.620-623, 1996.

FLORES, S.; GOSSET, G.; FLORES, N., DE GRAFF, A. A.; BOLIVAR, F. Analysis of carbon metabolism in Escherichia coli strains with an inactive phosphotransferase system by 13C labeling and NMR spectroscopy. Metab. Eng., v.41, p.24-137, 2002.

FRUNZKE, J.; ENGELS, V.; HASENBEIN, S.; GÄTGENS, C.; BOTT, M. Co-ordinated regulation of gluconate catabolism and glucose uptake in Corynebacterium glutamicum by two functionally equivalent transcriptional regulators, GntR1 and GntR2. Mol. Microbiol., v.67, p.305-322, 2008.

GAO, Q.; ZHANG, M.; MCMILLAN, J. D.; KOMPALA, D. S. Characterization of heterologous and native enzyme activity profiles in metabolically engineered Zymomonas mobilis strains during batch fermentation of glucose and xylose mixtures. Appl Biochem Biotechnol., v.98, p. 341-355, 2002.

GARROTE, G.; DOMINGUEZ, H.; PARAJO, J.C. Interpretation of deacetylation and hemicellulose hydrolysis during hydrothermal treatments on the basis of the severity factor. Process Biochem., v.37, p.1067-1073, 2002.

GOMES, R. S. Obtenção de mutantes deficientes no acúmulo de PHA e construção de linhagens recombinantes para o controle da composição monomérica. 100 f. Tese (Doutorado em Biotecnologia) - Universidade de São Paulo, Instituto Butantã, Instituto de Pesquisas Tecnológicas, São Paulo, 2009.

GOMEZ, J. G. C. Produção por Pseudomonas sp de polihidroxialcanoatos contendo monômeros de cadeia média a partir de carboidratos: Avaliação da eficiência, modificação da composição e obtenção de mutantes. $155 \mathrm{f}$. Tese (Doutorado em Microbiologia) - Instituto de Ciências Biomédicas, São Paulo, 2000.

GOMEZ, J. G. C.; RODRIGUES, M. F. A.; Alli, R. C. P.; TORRES, B. B.; BUENO NETTO, C. L.; SILVA, L. F. Evaluation of soil gram-negative bactéria yielding polyhydroxyalkanoate acids from carbohydrates and propionic acid. Appl. Microbiol. Biotechnol., v.45, p.785-791, 1996.

GÖRKE, B.; RAK, B. Catabolite control of Escherichia coli regulatory protein BglG activity by antagonistically acting phosphorylations. EMBO J., v.18, p.3370-3379, 1999.

GÖRKE, B.; STÜLKE, J. Carbon catabolite repression in bacteria: many ways to make the most out of nutrients. Nature Rev., v.6; p.613-624, 2008

GOSH, P.; SINGH, A. Psysicochemical and biological treatments for enzimatic/microbial conversion of lignocelulose biomass. Adv. Appl. Microbiol., v.39, p.295-333, 1993.

GOSSET, G. Improvement of Escherichia coli production strains by modification of the phosphoenolpyruvate:sugar phosphotransferase system. Microbial Cell Fact., v.4, p.14-24, 2005.

GREGORY, M. R. Environmental implications of plastic debris in marine settings-entanglement, ingestion, smothering, hangers-on, hitch-hiking and alien invasions. Philos. Trans. R. Soc. B., v.364, p.2013-2025, 2009.

GU, Y.; LI, J.; ZHANG, L.; CHEN, J.; NIU, L.; YANG, Y.; YANG, S.; JIANG, W. Improvement of xylose utilization in Clostridium acetobutylicum via expression of the talA gene encoding transaldolase from Escherichia coli. J. Biotechnol., v.143, p.284-287, 2009.

HANSON, K. G.; STEINHAUER, K.; REIZER, J.; HILLEN, W.; STÜLKE, J. HPr kinase/phosphatase of Bacillus subtilis: expression of the gene and effects of mutations on enzyme activity, growth and carbon catabolite repression. Microbiology, v.148, p.1805-1811, 2002.

HARDING, K. G.; DENNIS, J. S.; VON BLOTTNITZ, H.; HARRISON, S. T. L. Environmental analysis of plastic production processes: comparing petroleum-based polypropylene and polyethylene with biologically-based poly- $\beta$ hydroxybutyric acid using life cycle analysis. J. Biotechnol., v.130, p.57-66, 2007.

HARMAN, J. G.; Allosteric regulation of the cAMP receptor protein. Biochim. Biophys. Acta, v.1547, p. 1-17, 2001.

HAYWOOD, G. W.; ANDERSON, A. J.; CHU, L.; DAWES, E. A. Characterization of two 3-ketothiolases possessing differing substrate specificities in the polyhydroxyalkanoate synthesizing organism Alcaligenes eutophus. FEMS Microbiol. Lett., v.53, p.91-96, 1988. 
HAZENBERG, W.; WITHOLT, B. Efficient production of medium-chain-length poly-(3-hydroxyalkanoates) from octane by Pseudomonas oleovorans: economic considerations. Appl. Microbiol. Biotecnol., v.48, p.588-596, 1997.

HERNÁNDEZ-MONTALVO, V.; BOLIVAR, F.; GOSSET, G.. Characterization of sugar mixtures utilization by an Escherichia coli mutant devoid of the phosphotransferase system. Appl. Microbiol. Biotechnol.. v.57, p.186-191, 2001.

HERnÁNDEZ-MONTALVO, V.; MARTINEZ, A.; HERNANDEZ-CHAVEZ, G.; BOLIVAR, F.; VALLE, F.; GOSSET, G. Expression of galP and glk in an Escherichia coli PTS mutant restores glucose transport and increases glycolytic flux to fermentation products. Biotechnol. Bioeng., v.83, p.687-694, 2003.

HOPEWELL, J.; DVORAK, R.; KOSIOR, E. Plastics recycling: challenges and opportunities. Philos. Trans. R. Soc. B. v.364, p.2115-2126, 2009.

INADA, T.; KIMATA, K.; AIBA, H. Mechanism responsible for glucose-lactose diauxie in Escherichia coli: challenge to the cAMP model. Genes Cells, v.1, p.293-301, 1996.

IPCC - INTERGOVERNMENTAL PANEL ON CLIMATE CHANGE. Climate change 2001: the scientific basis. Disponível em: <http://www.ipcc.ch/pub/un/ipccwg1s.pdf>. Acesso em: 13 de jan. 2004

JUNG, Y. K.; KIM, T. Y.; LEE, S. Y. Metabolic engineering of Escherichia coli for the production of polylactic acid and its copolymers. Biotechnol. Bioeng., v.105, p.161-171, 2010.

LAARSSON, S.; PALMQVIST, E.; HAGERDAL, B.; TENGBORG, C.; STENBERG, K.; ZACCHI, G.; NILVENBRANT, N.O. The generation of fermentation inhibitors during dilute acid hydrolysis of softwood. Enzyme Microb. Technol., v.24, p.151-159, 1999.

LAWFORD, H. G.; ROSSEAU, J. D. Performance testing of Zymomonas mobilis metabolically engineered for cofermentation of glucose, xylose, and arabinose. Appl. Biochem. Biotech., v.98, p.429-448, 2002.

LEE, J. Biological conversion of lignocellulosic biomass to ethanol. J. Biotechnol., v.56, p.1-24, 1997.

LEE, Y. S. Poly(3-hydroxybuturate) production from xylose by recombinant Escherichia coli. Biosyt. Eng., v.18, p.397-399, 1998.

LEE, S. Y. Bacterial Polyhydroxyalkanoates. Biotech. Bioeng., v.49, p. 1-14, 1996.

LEE, S. Y.; CHOI, J. I.; SONG, J. Y. Removal of endotoxin during purification of poly(3-Hydroxybutyrate) from Gram-negative bacteria. J. Appl. Microbiol., v.65, p.2762-2764, 1999.

LI, R.; CHEN, Q.; WANG, P.G.; Qi, Q. A novel-designed Escherichia coli for the production of various polyhydroxyalkanoates from inexpensive substrate mixture. Appl .Microbiol. Biotechnol., v.75, p.1103-1109, 2007.

LINDSAY, S. E.; BOTHAST, R. J.; INGRAM, L. O. Improved strains of recombinant Escherichia coli for ethanol production from sugar mixtures. Appl. Microbiol. Biolechnol., v.43, p. 70- 75, 1995.

LÖNN, A.; TRÄFF-BJERRE, K. L.; CORDERO-OTELO, R. R.; VAN ZYL, W. H.; HAHN-HÄGERDAL, W. H. Xylose isomerase activity influences xylose fermentation with recombinant Saccharomyces cerevisiae strains expressing mutated xylA from Thermus thermophilus. Enzyme Microb. Technol.,. v.32, p.567-573, 2003.

LORCA, G. L.; CHUNG, Y. J.; BARABOTE, R. D.; WEYLER, W.; SCHILling, C. H.; SAIER, M. H. JR. Catabolite Repression and activation in Bacillus subtilis: dependency on CcpA, HPr, and HprK. J. Bacteriol., v.87,: p.7826-7839, 2005.

LU, C.; JEFFRIES, T. Shuffling of promoters for multiple genes to optimize xylose fermentation in an engineered Saccharomyces cerevisiae strain. Appl. Envirom. Microbiol., v.73, p.6072-6077, 2007.

LUX, R.; JAHREIS, K.; BETTENBROCK, K.; PARKINSON, J.S.; LENGELER, J.W. Coupling the phosphotransferase system and the methyl-accepting chemotaxis protein-dependent chemotaxis signaling pathways of Escherichia coli. Proc Natl Acad Sci U.S.A., v.92, p.11583-11587, 1995.

KAHAR, P., TSUGE, T., TAGUCHI, K., DOI, Y. High yeld production of polyhydroxyalkanoates from soybean oil by Ralstonia eutropha and its recombinant strain. Pol. Degradat. Stabil., v.83, p.79-86, 2003. 
KALENDAR, R.; LEE, D.; SCHULMAN, A. H. FastPCR software for PCR primer and probe design and repeat search. Genes, Genomes and Genomics, v.3, p.1-14, 2009.

KAMM, B; KAMM, M. Principles of biorefineries. Appl. Microbiol. Biotechnol., v.64: p.137-145, 2004.

KAMM, B.; GRUBER, P. R.; KAMM, M. Biorefineries - industrial processes and products. status quo and future. Wienheim: Wiley-VCH, 2006. 3v.

KARIMOVA, G.; LADANT, D.; ULLMANN, A. Relief of catabolite repression in a cAMP-independent catabolite gene activator mutant of Escherichia coli. Research Microbiol., v.155, p.76-79, 2004.

KEATING, J. D.; PANDANIBAN, C.; MANSFIELD, S. D Tolerance and adaptation of ethanologenic yeasts to lignocellulosic inhibitive compounds. Biotech. Bioeng., v.93, p.1196-1206, 2006.

KEENAN, T. M.; NAKAS, J. P.; TANENBAUM S. W. Polyhydroxyalkanoate copolymers from forest biomass. J. Ind. Microbiol. Biotechnol., v.33, p.616-626, 2006.

KEENAN, T. M.; TANENBAUM, S. W.; STIPANOVIC, A. J.; NAKAS, J. P. Production and characterization of poly- $\beta$-hydroxyalkanoate copolymers from Burkholderia cepacia utilizing xylose and levulinic. Acid. Biotechnol. Prog. v.20, p.1697-1704, 2004.

KIM, B. S.; LEE, S. C.; LEE, S. Y.; CHANG, H. N.; CHANG, Y. K.; WOO, S. I. Production of poly-3-hydroxybutyric acid by fed-batch culture of Alcaligenes eutrophus with glucose concentration control. Biotechnol. Bioeng., v.43, p.892-898, 1994

KIM, H. J., ROUX, A., SONESHEIN, A. L. Direct and indirect roles of CcpA in regulation of Bacillus subtilis Krebs cycle genes. Mol. Microbiol., v.45, p.179-190, 2002.

KONSTANTINOV, K.; KISHIMOTO, M.; SEKI, T.; YOSHIDA, T. A balanced DO-stat and its application to the control of acetate excretion by recombinant Escherichia coli. Biotechnol. Bioeng., v.36, p.750-758, 1990.

KOVACH, M. E.; ELZER, P. H.; Hill, D. S. Four new derivatives of the broad-host-range cloning vector pBBR1MCS, carrying different antibiotic-resistance cassettes. Gene, v.166, p.175-176, 1995.

LULKO, A. T.; BUIST, G.; KOK, J.; KUIPERS, O. P. Transcriptome analysis of temporal regulation of carbon metabolism by CcpA in Bacillus subtilis reveals additional target genes. J. Mol. Microbiol. Biotechnol., v.12, p.8295, 2007.

MAJEWSKI, R. A.; DOMACH, M. M. Simple constrained-optimization view of acetate overflow in Escherichia coli. Biotechnol. Bioeng., v.35, p.732-738, 1990.

MARTIN, C.; ALRIKSSON, B.; SJODE, A.; NILVEBRANT, N. O.; JONSSON, A. Dilute sulfuric acid pretreatment of agricultural and agro-industrial residues for ethanol production. Appl. Biochem. Biotechnol., v.136, p. 339-352, 2007.

MARTIN, C.; GALBE, M.; WAHLBOM, C. F., HAHN-HÄGERDAL, B; JÖNSON, L. J. Ethanol production from enzymatic hydrolysates of sugarcane bagasse using xylose-utilising Saccharomyces cerevisiae. Enzyme Microb. Technol., v.31, p.274-282, 2002.

MARTIN, C.; JONSSON, L. J. Comparison of the resistance of industrial and laboratory strains of Saccharomyces and Zygosaccharomyces to lignocellulose-derived fermentation inhibitors. Enzyme Microb. Technol.,, v.32, p.386-395, 2003.

MARTINEZ, A.; RODRIGUEZ, M.; YORK, S. W.; PRESTON, J. F.; INGRAM, L. O. Effects of Ca(OH $)_{2}$ treatments ("overliming") on the composition and toxicity of bagasse hemicellulose hydrolysates. Biotechnol. Bioeng., v. 69, p. 526-536, 2000.

MATSUDA, T.S. Isolamento de bactérias produtoras de polihidroxialcanoatos de cadeia curta e média a partir de óleos vegetais. 81 f. Dissertação (Mestrado em Biotecnologia) Universidade de São Paulo/Instituto Butantã/Instituto de Pesquisas Tecnológicas, São Paulo, 2009. 
MEIJNEM, J.P.; WINDE, J.H.; RUIJSSENAARS, H.J. Engineering Pseudomonas putida S12 for efficient utilization of D-Xylose and L-Arabinose. Appl. Envirom. Microbiol., v.74, p.5031-5037, 2008.

MISKO, T. P.; MITCHELL, W. J.; MEADOW, N. D.; ROSEMAN, S. Sugar transport by the bacterial phosphotransferase system. Reconstitution of inducer exclusion in Salmonella typhimurium membrane vesicles. J. Biol. Chem., v.262, p.16261-16266, 1987.

MONOD, J. Recherches sur la Croissance des Cultures Bacteriennes. 103 f. Tese de doutorado, Universidade de Paris, Paris, 1962.

MOSIER, N.; WYMAN, C.; DALE, B.; ELANDER, R.; LEE, Y. Y.; HOLTZAPPLE, M.; LADISCH, M. Features of promising technologies for pretreatment of lignocellulosic biomass. Bioresource Technol., v.96, p. 673-686, 2005.

NEIDHARDT F. C.; CURTIS, R.; INGRAHAM, J. L; LIN, E. C. C.; LOW, K. B.; MAGASANIK, B.; RESNIKOFF, W. S.; RILEY, M.; SCHAECHTER, M.; UMBARGER, H. E. Escherichia coli and Salmonella. Washington, DC: ASM Press, 1996. 2 v.

NICHOLS, N. N.; DIEN, B. S.; BOTHAST. Use of catabolite repression mutants for fermentation of sugar mixtures to ethanol. Appl. Microbiol. Biotechnol., v.56, p.120-125, 2001.

NICHOLSON, T. L., CHIU, K.; STEPHENS, R. S. Chlamydia trachomatis lacks an adaptive response to changes in carbon source availability. Infect. Immun., v.72, p.4286-4289, 2004.

NOGALES, J.; PALSSON, B.; THIELE, I. A genome-scale metabolic reconstruction of Pseudomonas putida KT2440: iJN746 as a cell factory. BMC Syst. Biol., v.2, p.1-20, 2008.

NONATO, R. V.; MANTELATO, P. E.; ROSSEL, C. E. V. Integrated production of biodegradable plastic, sugar and ethanol. Appl. Biotechnol., v.57: p.1-5, 2001.

NOVOTNY, M. J.; FREDERICKSON, W. L.; WAYGOOD, E. B.; SAIER, M. H. Jr. Allosteric regulation of glycerol kinase by enzyme III $^{\text {glc }}$ of the phosphotransferase system in Escherichia coli and Salmonella typhimurium. J Bacteriol., v.162, p.810-816. 1985.

OEDING, V.; SCHLEGEL, H.. $\alpha$-ketothiolase from Hydrogenomonas eutropha H-16 and its significance in the regulation of poly- $\beta$-hydroxybutyrate metabolism. Biochem. J., v.134, p.239-248, 1973.

PEIXOTO, R.M. Bioprospecção de microrganismos do gênero Pseudomonas produtores de biossurfactantes. 98 f. Dissertação (Mestrado em Microbiologia) Universidade de São Paulo, Instituto Butantã, Intstituto de Pesquisa Tecnológica, São Paulo, 2008.

PEREIRA, E.M. Avaliação da influência de genes do catabolismo de propionato sobre a síntese de copolímero biodegradável em Burkholderia sacchari e outras bactérias. Tese (Doutorado em Biotecnologia) Universidade de São Paulo, Instituto Butatã, Intstituto de Pesquisa Tecnológica, São Paulo, 2007.

PFEIFFER, T.; SANCHEZ-VALDENEBRO, I.; NUNO, J. C.; MONTERO, F.; SCHUSTER, S. METATOOL: for studying metabolic networks. Bioinformatics, v.15, p.251-257, 1999.

PALMQVIST, E.; HAHN-HAGERDAL, B. Fermentation of lignocellulosic hydrolysates II: inhibitors and mechanisms of inhibition. Bioresour. Technol., v.74, p.25-33, 2000a

PALMQVIST, E.; HAHN-HAGERDAL, B. Fermentation of lignocellulosic hydrolysates I: inhibition and detoxification. Bioresour. Technol., v.74, p.17-24, 2000 b.

PLUMBRIDGE, J. Regulation of gene expression in the PTS in Escherichia coli: the role and interactions of Mlc. Curr. Opin. Microbiol., v.5, p.187-193, 2002.

PRADELlA, J. G. C.; TACIRO, M. K.; PICCOLI. R. A. M.; SILVA, L. R.; AVÓ, M. R.; YU, A.S. O. Biopolímeros e intermediários químicos, p. 118 (Relatório Técnico $\mathrm{n}^{\circ} 84$ 396-205). Disponível em: <www.anbio.org.br/pdf/2/tr6/_biopolimeros.pdf>. Acesso em: 10 set. 2006.

RAMSAY, J.A.; ALY, H.M.C.; RAMSAY, B.A. Hemicellulose as a potential substrate for production of PHA. Can. J. Microbiol., v.41, p.262-266, 1995. 
REDDY, C. S. K.; GHAI, R.; KALIA, V. C. Polyhydroxyalkanoates: an overview. Bior. Technol. v.87, p.137-186, 2007.

SAMBROOK, J.; FRITSCH, E.F.; MANIATS, T. Molecular cloning: a laboratory manual. New York: Cold Spring Harbor Lab Press, 1989. 3v.

SASAKI, M.; JOJIMA, T.; MASAYUKI, I. Simultaneous utilization of D-cellobiose, D-glucose, and D-xylose by recombinant Corynebacterium glutamicum under oxygen-deprived conditions. Appl. Microbiol. Biotechnol., v.81, p.691-699, 2008.

SCHELL, D. J.; FARMER, J.; NEWMAN, M.; MCMILLAN, J. D. Dilute-sulfuric acid pretreatment of corn stover in pilot-scale reactor. App. Biochem. Biotech., v.105, p.69-85, 2003

SCHUMACHER, M. A.; ALLEN, G. S.; DIEL, M.; SEIDEL, G.; HILLEN, W.; BRENNAN, R.G. Structural basis for allosteric control of the transcription regulator CcpA by the phosphoprotein HPr-Ser46-P. Cell, v.11, p.731-741, 2004.

SCHUMACHER, M. A.; SEIDEL, G.; HILLEN, W.; BRENNAN, R. G. Structural mechanism for the fine-tuning of CcpA function by the small molecule effectors glucose 6-phosphate and fructose 1,6-bisphosphate. J. Mol. Biol., v.368, 1042-1050, 2007.

SENIOR, P. J.; DAWES, E. A. (1973). The regulation of poly- $\beta$-hydroxybutyrate metabolism in Azotobacter beijerinckii. Biochem. J., v.134, p.225-238, 1973.

SEOK, Y. .J.; KOO, B. M.; SONDEJ, M.; PETERKOFSKY, A. Regulation of E. coli glycogen phosphorylase activity by HPr. J. Mol. Microbiol. Biotechnol., v.3, p.385-393, 2001.

SILVA, L. F.; TACIRO, M. K.; MICHELIN, M. E. R.; CARTER, J. M.; PRADELLA, J. G. C.; GOMEZ, J. G. C. Poly-3-hydroxybutiyrate (P3HB) production by bacteria from xilose, glucose and sugarcane bagasse hydrolysate. Ind. Microbiol. Biotechnol., v.31, p.245-254, 2004.

SINGH, K. D.; SCHMALISCH, M. H.; STÜLKE, J.; GÖRKE, B. Carbon catabolite repression in Bacillus subtilis: quantitative analysis of repression exerted by different carbon sources. J. Bacteriol., p.7275-7284, 2008.

SONG, B. G.; Kim, T. K.; Jung, Y. M., Lee, Y. H. Modulation of talA gene in pentose phosphate pathway for overproduction of poly- $\beta$-hydroxybutyrate in transformant Escherichia coli harboring phbCAB operon. J. Biosc. Bioeng., v.102, p.237-240, 2006.

SONG, S.; Park, C. Utilization of D-ribose through D-xylose transporter. FEMS Microbiol. Lett., v.163, p.255-261, 1998.

SONG, J. H.; MURPHY, R. J; NARAYAN, R.; DAVIES, G. B. Biodegradable and compostable alternatives to conventional plastics. Philos. Trans. R Soc. B., v.364, p.2127-2139, 2009.

STEINBÜCHEL, A. Non-biodegradable biopolymers from renewable resources: perspectives and impacts. Curr. Opin. Biotechnol., v.16, p.607-613, 2005.

STEINBÜCHEL, A.; LUTKE-EVERSLOH, T. Metabolic engeneering and pathway construction for biotechnological production of relevant polyhydroxyalkanoates in microorganisms. Biochem. Eng. J., v. 16, p. 81-96, 2003.

STEINBÜCHEL, A.; VALENTIN, H.E. Diversity of bacterial polyhydroxyalkanoic acids. FEMS Microbiol. Letters, v.128, p.219-228, 1995.

STEPHANOPOULOS, G.; VALLINO, J. J. Network rigidity and metabolic engineering in metabolite overproduction. Science, v.252, p.1675-1681, 1991.

STÜLKE, J.; HILLEN, W. Regulation of carbon catabolism in Bacillus species. Annu. Rev. Microbiol., v.54; p. 849880. 
SUDESH, K.; ABE, H.; DOI, Y. Synthesis, structure and properties of polyhydroxyalkanoates: biological polyesters. Prog. Polym. Sci., v.25, p.1503-1555, 2000.

SONENSHEIN, A.L. Control of key metabolic intersections in Bacillus subtilis. Nat. Rev., v.5, p.917-927, 2008.

SUN, Y.; CHENG, J. Hydrolysis of lignocellulosic materials for ethanol production: a review. Bioresource Technol., v.83, p.1-11, 2002.

TACIRO, M. K. Processo continuo de produção de polihidroxialcanoatos de cadeia média (PHAmcl) sob limitação múltipla de nutrientes. 273 f. Tese (Doutorado em Biotecnologia) Universidade de São Paulo/Instituto Butantã/Instituto de Pesquisa Tecnológica, São Paulo, 2008.

TANAKA, K.; KATAMUNE, K; ISHIZAKI A. Fermentative production of poly( $\beta$-hydroxybutyric acid) from xylose via lactate by a two-stage culture method employing Lactococcus lactis IO-1 and Alcaligenes eutrophus. Can. J. Microbiol. v.41, p.257-261, 1994

TITGEMEYER, F.; MASON, R E; SAIER, M. H. Jr.Regulation of the raffinose permease of Escherichia coli by the glucose-specific enzyme IIA of the phosphoenolpyruvate:sugar phosphotransferase system. J. Bacteriol. v.176, p.543546, 1994.

THOMPSON, R. C.; MOORE, C. J.; VOM SAAL, F. S.; SWAN S. H. Plastics, the environment and human health: current consensus and future trends. Philos. Trans. R. Soc. B., v.364, p.2153-2166, 2009.

THOMPSON, R. C.; OLSON, Y.; MITSCHELL, R. P.; DAVIS, A.; ROWLAND, S. J.; JOHN, A. W.; MCGONIGLE, D.; RUSSEL, A. E. Lost at sea: where is all the plastic? Science, v.304, p.838, 2004.

VALAPPIL, S. P.; BOCCACCINI, A. R.; BUCKE, C.; IPSITA, R. Polyhydroxyalkanoates in Gram-positive bacteria: insights from the genera Bacillus and Streptomyces. Antonie van Leeuwenhoek. v.91, p.1-17, 2007.

VAN DYME, D. L.; BLASÉ, M. G.; CLEMENTS, L. D (1999) A strategy for returning agriculture and rural America to long-term full employment using biomass refineries. In: Janeck $J$ (ed) Perspectives on new crops and new uses. Alexandria, Va: ASHS Press, 1999. p. 114-123.

VAN-THUOC, D.; QUILLAGUAMA, J.; MAMO, G.; MATTIASSON, B.Utilization of agricultural residues for poly(3-hydroxybutyrate) production by Halomonas boliviensis LC1. J. Appl. Microbiol., v.104, p.420-428, 2008.

VASCONCELOS, Y. Dergradação difícil. Revista Fapesp v.152, p. 17-19, 2008

WACKER, I., LUDWIG, H., REIF, I., BLENCKE, H. M., DETSCH, C., STÜLKER, J. The regulatory link between carbon and nitrogen metabolism in Bacillus subtilis: regulation of the gltAB operon by the catabolite control protein CcpA. Microbiology, v.149, p.3001-3009, 2003.

WHITE, D. The physiology and biochemistry of prokaryotes. Oxford: Oxford University Press; 2 ed., 2000. p565.

WILKIE, A. C.; RIEDESEL, K. J.; OWENS, J. M. Stillage characterization and anaerobic treatment of ethanol stillage from conventional and cellulosic feedstocks. Biomass Bioenergy, v.19, p.63-102, 2000.

YOUNG, F. K.; KASTNER, J. R.; MAY, S. W. Microbial production of poly- $\beta$-hydroxybutiric acid form $D$-xylose and lactose by Pseudamonas cepacia. Appl. Environ. Microbiol.n v.60, p.4195-4198, 1994.

YAN, F.; YANG, N.; PANG, H.; LIAO, B. Production of levulinic acid from bagasse and paddy straw by liquefaction in the presence of hydrochloride acid. Cleanm v. 36, p.158 - 163, 2008.

YU, J.; CHEN, L. X. The greenhouse gas emissions and fossil energy requirement of bioplastics from cradle to gate of a biomass refinery. Environ. Sci. Technol., v.15, p.6961-6966, 2008.

YU, J.; STAHL, H. Microbial utilization and biopolyester synthesis of bagasse hydrolysates. Bioresour. Technol., v.99, p.8042-8048, 2008. 
XU, F.; SUN, J. X.; LIU, C. F.; SUN, R. C. Comparative study of alkali- and acidic organic solvent-soluble hemicellulosic polysaccharides from sugarcane bagasse. Carbohyd. Res., v.341, p.235-261, 2006.

ZHANG, X.; JANTAMA, K. T.; SHANMUGAM, K. T.; INGRAM, L. O. Re-Engineering Escherichia coli for succinate production in mineral salts medium. Appl. Environ. Microbiol., v. 75, p. 7807-7813, 2009. 